\title{
Rheology of Green Self-Consolidated Concrete (GSCC) with Ternary Blend under Coupled Effects of Temperature and Prolonged Mixing
}

\author{
Samer Al-Martini ${ }^{1,}$, and Mohammed Al-Khatib ${ }^{2}$ \\ ${ }^{1}$ Department of Civil Engineering, College of Engineering, Abu Dhabi University, Abu Dhabi, UAE \\ ${ }^{2}$ Lab Teaching Assistant of Civil Engineering, College of Engineering, AlHosn University, Abu \\ Dhabi, UAE
}

\begin{abstract}
The fresh quality of a concrete mixture subjected to high temperature and prolonged mixing is adversely affected. These harsh conditions would result in a stiff concrete that is hard to handle and place. This paper investigates the coupled effects of temperature and prolonged mixing on green self-consolidating concrete (GSCC) incorporating a ternary blend of fly ash and silica fume. This study was carried out in the construction material laboratory of Abu Dhabi University under an outdoor environment during the summer of 2014. The SCC mixtures were continuously mixed for 110 minutes at a temperature ranging from 25 to 40 ${ }^{\circ} \mathrm{C}$ to simulate the actual conditions of concrete during transporting to a construction site. The fresh properties were tested using BT2 portable rheometer, slump flow, $\mathrm{T}_{50}$ and visual stability index (VSI). The results showed that the ternary blend of silica fume and fly ash enhanced the rheological properties of SCC mixtures under high temperature and prolonged mixing time.
\end{abstract}

\section{Introduction}

Concrete mixtures, in United Arab Emirates (UAE) during summer, are usually subjected to both high temperature and prolonged mixing during its transportation to construction sites. These harsh conditions would adversely affect the fresh and hardened properties of concrete. As such, concrete in a transit truck would arrive to the construction site with low quality, and may not meet the job requirements for placement and consolidation. Consequently, such concrete shipment is most likely rejected, resulting in delaying the construction process, wasting materials and affecting the environment.

Several researchers investigated the coupled effects of temperature and prolonged mixing on self-consolidating concrete (SCC). For instance, Al-Martini and Al-Khatib [1], investigated the effect of incorporating fly ash, as partial replacement of cement by mass, on self-consolidating concrete (SCC) under extreme conditions (high temperature and prolonged continuous mixing). They reported that the addition of fly ash alleviated the negative effect of temperature and mixing time on the flowability of SCC mixtures. It was

* Corresponding author: samer.almartini@adu.ac.ae 
also documented that SCC mixtures with fly ash had better strength and durability than the reference mixture (i.e., SCC with $100 \%$ cement).

Al-Khatib and Al-Martini [2] studied the effect of incorporating silica fume by mass of cement on SCC mixtures under hot weather and prolonged mixing. The results showed that the slump flow was adversely affected by the temperature and prolonged mixing. Also, the presence of silica fume improved the compressive strength and chloride penetration resistance of SCC mixtures, when compared to the controlled mixtures.

Al-Martini and Nehdi [3] investigated the coupled effects of mixing time and ambient temperature on the slump flow and compressive strength of self-consolidating concrete (SCC). They found that the slump flow decreased with an increased mixing time, while the compressive strength increased with continuous mixing time. The results also revealed that SCC mixtures with slump flow in the range of 400 and $600 \mathrm{~mm}$ had superior compressive strength compared with mixtures with slump value lower or higher than that range.

The current research investigates the coupled effects of temperature and prolonged mixing on the rheology of self-consolidating concrete incorporating a ternary blend of supplementary cementitious materials (SCMs), namely fly ash and silica fume, as partial replacement of cement by mass. The mixtures were continuously mixed for 110 minutes under ambient temperature ranging from $25{ }^{\circ} \mathrm{C}$ to $40{ }^{\circ} \mathrm{C}$. The main goal of the study is to depict the effect of ternary blend of silica fume and fly ash on SCC mixtures under extreme conditions.

\section{Experimental program}

Locally available coarse and fine aggregates were used in this study. The coarse aggregates were with $10 \mathrm{~mm}$ nominal maximum size. Type I Portland cement, fly ash and silica fume in accordance with ASTM C 150 and ASTM C $618[4,5]$ were used. A second generation polycarboxylate-based high range water reducing admixture $(\mathrm{PCH})$ following the ASTM C 494 type F requirements at a dosage of $1.8 \%$ was incorporated in the SCC mixtures [6]. It should be noted that concrete mixtures with no supplementary materials (i.e., $100 \%$ cement) were denoted as SCC in the paper, and those incorporating ternary blend were denoted as GSCC.

The concrete was continuously mixed for 110 minutes in a concrete drum mixer. The experiments were conducted during the summer of 2014 in Abu Dhabi. For temperature of $25^{\circ} \mathrm{C}$, concrete was mixed in the construction materials lab with a controlled environment, and for the other tested temperatures $\left(30,35\right.$, and $\left.40{ }^{\circ} \mathrm{C}\right)$ the concrete was mixed out door. The mixing procedure used in this research adopted the one presented by Al-Martini and Nehdi [3]. The coarse and fine aggregates were stored in the same environment of mixing for 24 hours before mixing. The rheology, slump flow, $\mathrm{T}_{50}$, and visual stability index (VSI), were tested at an interval of 30 min with accordance to ASTM C 1611 [7].

\section{Rheology test}

In this study, BT2 rheometer was used to evaluate the rheological properties of the SCC mixtures investigated. It is a small portable device with an impeller geometry, which can be easily handled and used onsite. Its container can accommodate a concrete sample with a volume up to 20 liters. It needs just one rotational cycle to measure the rheological properties of concrete. The rheometer used in this study measures the torque of concrete at several rotational speeds ranging from 0 to $4 \mathrm{~m} / \mathrm{s}$. It should be noted that the BT2 rheometer produces the results in relative values (i.e., relative viscosity (N. s) and relative yield stress (N.m) [8]. The relative yield stress and the relative plastic viscosity are measured using the 
flow curves produced by the BT2 rheometer. The relative yield stress is the intercept of the fitted data line with the torque axis, and relative viscosity is the slope of that line. The torque of SCC and GSCC mixtures increases linearly with the increase of the flow rate. This relation can be expressed by:

$$
T=g+h N
$$

where $T$ is the torque (N.m), $g$ is the flow resistance (N.m), $h$ is the viscosity factor (N.s), and $N$ is the rotational speed $(\mathrm{m} / \mathrm{s})$.

\section{Results and discussion}

\subsection{Effect of temperature and mixing time on relative viscosity of SCC and GSCC mixtures}

Fig. 1 shows the effect of temperature on the relative viscosity of SCC and GSCC mixtures. The ambient temperature ranged from 25 to $45{ }^{\circ} \mathrm{C}$. Figure 1a shows data after short mixing time $(20 \mathrm{~min})$. In general, the relative viscosity increased with increasing temperature for all mixtures as shown in Fig. 1 (a). At low and moderate temperatures $\left(25\right.$ and $30{ }^{\circ} \mathrm{C}$ ), GSCC mixtures with ternary blend had higher relative viscosities than that for SCC mixtures with $100 \%$ cement, while at high temperatures $\left(35^{\circ} \mathrm{C}\right.$ and $\left.40{ }^{\circ} \mathrm{C}\right)$, the GSCC mixtures had lower relative viscosities than that for the SCC mixtures.

The results of the SCC and GSCC mixtures after $110 \mathrm{~min}$ of continuous mixing are shown in Fig. 1 (b). The results show that the GSCC mixtures containing ternary blend had lower relative viscosity than that for the SCC mixtures with $100 \%$ cement at all temperatures. This indicates that the relative viscosity of the GSCC mixture (with ternary blend) was highly sensitive to the prolonged mixing compared to the SCC mixture (with $100 \%$ cement). It can be further observed that the relative viscosity of mixtures after prolonged mixing was higher than that after short mixing for all temperatures.
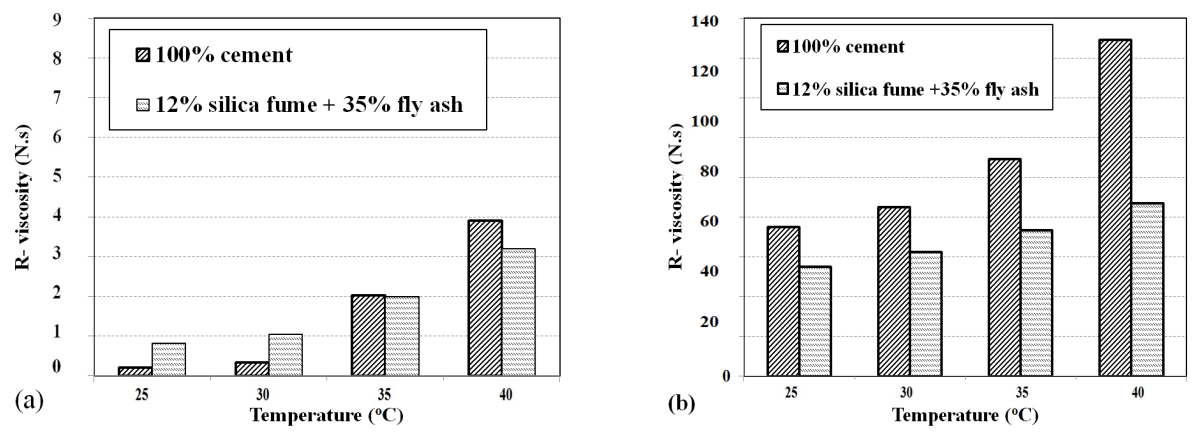

Fig. 1. Relative viscosity of SCC and GSCC mixtures: at (a) $20 \mathrm{~min}$ and (b) $110 \mathrm{~min}$

\subsection{Effect of temperature and mixing time on relative yield stress of SCC and GSCC mixtures}

The relative yield stress values of GSCC mixture incorporating a ternary blend of silica fume and fly ash (35\% fly ash and silica fume at $12 \%)$ are illustrated in Fig. 2. Data results for control mixtures (SCC with 100\% cement) are also presented in the figure. In general, the relative yield stress increased with a higher temperature for short and long continuous 
mixing. After short mixing time (20 min), the relative yield stress for GSCC mixtures was higher than that of SCC mixture at all temperatures (Fig. 2 (a)). Fig. 2 (b) shows the effect of temperature on the relative yield stress after $110 \mathrm{~min}$ of continuous mixing. Similar to the short mixing time, the yield stress values of SCC mixtures were higher than that of GSCC mixture at all mixing temperatures.
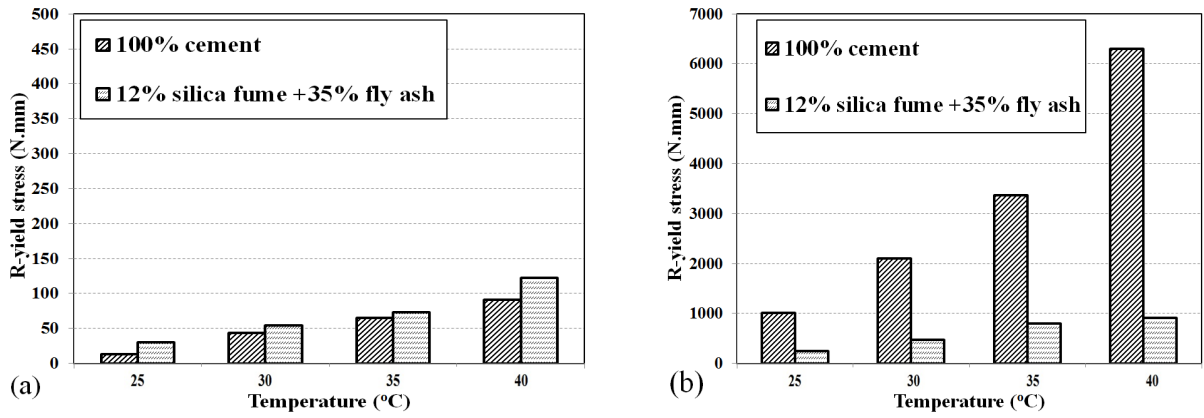

Fig. 2. Relative yield stress of SCC and GSCC mixtures: at (a) $20 \mathrm{~min}$ (b) $110 \mathrm{~min}$

\subsection{Effect of temperature and mixing time on slump flow, $\mathrm{T}_{50}$, and VSI of SCC and GSCC mixtures}

Table 1 shows the results of slump flow, flow rate $\left(\mathrm{T}_{50}\right)$, and visual stability index (VSI) of SCC and GSCC mixtures at temperature ranging from 25 to $40{ }^{\circ} \mathrm{C}$ and prolonged mixing for up to $110 \mathrm{~min}$. The results show that, in general, the slump flow values and flow rate $\left(\mathrm{T}_{50}\right)$ values decreased with increasing temperature and mixing time, while the stability (VSI) improved.

Table 1. Slump flow, Flow rate $\left(\mathrm{T}_{50}\right)$, and VSI results of SCC mixtures incorporating ternary blend

\begin{tabular}{|c|c|c|c|c|c|c|c|c|c|}
\hline \multicolumn{2}{|c|}{ Temperature ${ }^{\circ}$ C } & \multicolumn{2}{c|}{25} & \multicolumn{2}{c|}{ 30 } & \multicolumn{2}{c|}{35} & \multicolumn{2}{c|}{40} \\
\hline \multirow{2}{*}{ Mixtures } & Test & 20 & 110 & 20 & 110 & 20 & 110 & 20 & 110 \\
\hline \multirow{5}{*}{$100 \%$ CEMENT } & $\begin{array}{c}\text { Slump } \\
\text { flow } \\
(\mathrm{mm})\end{array}$ & 843 & 295 & 794 & 276 & 691 & 210 & 675 & 343 \\
\cline { 2 - 11 } & $\begin{array}{c}\mathrm{T}_{50} \\
(\mathrm{~s})\end{array}$ & 1.9 & - & 4 & - & 10.9 & - & 18.1 & - \\
\cline { 2 - 11 } & VSI & $(3)$ & $(1)$ & $(3)$ & $(0)$ & $(2)$ & $(0)$ & $(2)$ & $(0)$ \\
\hline & $\begin{array}{c}\text { Slump } \\
\text { flow } \\
(\mathrm{mm})\end{array}$ & 774 & 550 & 709 & 469 & 676 & 412 & 619 & 396 \\
\cline { 2 - 11 } & $\begin{array}{c}\mathrm{T}_{50} \\
(\mathrm{~s})\end{array}$ & 9.6 & 87 & 14.5 & - & 18.6 & - & 29 & - \\
\cline { 2 - 10 } & VSI & $(2)$ & $(0)$ & $(1)$ & $(0)$ & $(0)$ & $(0)$ & $(0)$ & $(0)$ \\
\hline
\end{tabular}

It can be observed that the presence of the ternary blend of silica fume and fly ash in concrete enhanced the stability of the SCC mixtures, when compared with the $100 \%$ cement mixture. After short mixing time (20 min), the slump flow values and the $T_{50}$ values of GSCC mixtures were slightly lower than that of SCC mixtures. However, incorporating the ternary blend of fly ash and silica fumes improved the slump flow and $\mathrm{T}_{50}$ after long 
mixing as evidenced from the higher slump values for the GSCC mixtures after $110 \mathrm{~min}$ of continuous mixing. It should be noted that some data results of $\mathrm{T}_{50}$ after long mixing time are missing in the table, because those mixtures became stiff, and their slump flow did not reach the $500 \mathrm{~mm}$ diameter. Based on these results, it can be argued that ternary blend ( $30 \%$ fly ash and $12 \%$ silica fume) is beneficial for SCC mixtures subjected to prolonged mixing time.

\section{Conclusion}

The coupled effects of temperature and mixing time on the rheological properties of SCC mixtures with $100 \%$ cement and green self-consolidating concrete mixtures (GSCC) incorporating a ternary blend of silica fume and fly ash was investigated. The water to cementitious ratio was kept constant $(\mathrm{w} / \mathrm{c}=0.36)$. A constant dosage of polycarboxylatebased high range water reducing admixture was incorporated in all mixtures to maintain adequate initial slump flow. Based on the experimental results, the following can be concluded:

i) The slump flow decreased with increasing the temperature and mixing time.

ii) The combination of fly ash and silica fume improved the stability of SCC mixtures.

iii) The relative viscosity of the SCC mixtures with $100 \%$ cement was more sensitive to the prolonged mixing than the ternary blend mixture (GSCC).

iv) The relative yield stress increased with increasing temperature for all mixing times.

v) It can be argued that ternary blend of fly ash and silica fume is beneficial for SCC mixtures under prolonged mixing time as the slump flow and $\mathrm{T}_{50}$ improved.

The authors would like to acknowledge the financial support of Abu Dhabi University (ADU), Grant received in 2015 from the Centre of Excellence on Sustainable Built Environment at ADU (cost center No. 19300078). Thanks are also due to a number of admixtures, additives and aggregates suppliers who contributed materials used in this investigation.

\section{References}

[1] S. Al-Martini and M. Al-Khatib, An experimental study on self-consolidating concrete (SCC) under hot weather and hauling time, Key Engineering Materials J., 677, 3-7 (2016)

[2] M. Al-Khatib and S. Al-Martini, Experimental investigation on the effect of silica fume on green self-consolidating concrete under extreme conditions, Proc. of Advances and Trends in Engineering Materials and their Applications, Toronto, (2016)

[3] S. Al-Martini and M. Nehdi, Effects of heat and mixing time on self-compacting Concrete, ICE Construction Materials J., 163, 175-182 (2010)

[4] ASTM C150 / C150M-16e1, Standard specification for portland cement, ASTM International, West Conshohocken, (2016)

[5] ASTM C618-15, Standard specification for coal fly ash and raw or calcined natural pozzolan for use in concrete, ASTM International, West Conshohocken, (2015)

[6] ASTM C 494-05a, Standard specification for chemical admixtures for concrete, ASTM International, West Conshohocken, (2005)

[7] ASTM C 1611/C 1611M-05, Standard test method for slump-flow of self consolidating concrete, ASTM International, West Conshohocken, (2005)

[8] E. Koehler, Aggregates in Self-Consolidating Concrete, PhD Thesis, The University of Texas, Austin, (2007) 